\title{
Striving Toward a Circular Economy: A Case Study of a Zero Single-Use Plastic Policy in Pearl of the Orient (Penang)
}

\author{
Corry Maciej Glanowski* \\ University of Glasgow \\ Glasgow, United Kingdom \\ glanowskimaciej@gmail.com
}

\author{
Ramona Blanes \\ University of Glasgow \\ Glasgow, United Kingdom \\ Ramona.Blanes@glasgow.ac.uk
}

\author{
Cheng Ling Tan \\ Universiti Sains Malaysia \\ Penang, Malaysia \\ tanchengling@usm.my
}

\begin{abstract}
This study aims to explore how the state of Penang could enhance a circular approach to single-use plastic by implementing a new federal policy (Malaysia's Roadmap Towards Zero Single-Use Plastic 2018-2030). The study involves twelve semi-structured interviews with key stakeholders, including representatives from both the state and the federal governments, city council, producers, manufacturers, NGOs and the recycling facilities. The study clarifies what a zero single-use plastic policy means, presents alternatives to conventional single-use plastic as well as introduces several means of enhancing a circular approach towards single-use plastic such as improved waste management system, stakeholders' engagement, Extended Producer Responsibility, effective policy enforcement, a need for clearer communications along with identifying measurable Key Performance Objectives.
\end{abstract}

Keywords: circular economy, single-use plastic, policymaking, change management

\section{INTRODUCTION}

The study aims to explore how the state of Penang can move towards a zero single-use plastics (SUP) by 2030 to comply with a new federal environmental policy. Plastic waste has become a major problem in Malaysia as the country is ranked as one of the top mismanaged plastic waste destinations in the world [1]. To address the issue, the government of Malaysia has proposed a new environmental policy to curb single-use plastic by 2030 (Malaysia's Roadmap Towards Zero Single-Use Plastics 2018-2030). The policy aims to curb plastic pollution by either replacing or banning single-use plastic items in the country. The strategic change is rather complex and requires numerous stakeholders to be on board. Hence, a sophisticated understanding of the stakeholders' perspectives to achieve this mission by 2030 is required. This study explores the definition of zero SUP from the perspectives of the various stakeholders, available alternatives to conventional plastic, and recommendations for Penang on how to enhance a circular approach towards SUP.

\section{MATERIALS AND METHODS}

\section{A. Literature Review}

As the modern economy is heavily rooted in plastic manufacture, many advocate for a transition from a linear to a circular economy. The concept can be defined as an economic development model which aims to increase resource-utilization efficiency and environmental efficiency as well as reduce the dependence of economic development on limited natural resources [2]. Indeed, it may be possible for reusable packaging to create substantial cost savings, and if used in pooled systems across companies and industries, significant value beyond packaging could be created [3]. A major challenge, therefore, exists to develop alternative and targeted and circular waste management systems to promote the integration of plastic into a circular economy [4]. Traditionally, this is achieved through legislation, regulations and policies [5] such as adopting special taxes/bans [6] engaging with producers to create a deposit scheme for plastic bottles [7] or incentivizing production of biodegradable materials to replace conventional plastic [8] as well as it is about raising awareness amongst the public about plastic pollution [9] and educating the public [10]. All the above reinforce the crucial role of authorities and policymakers when tackling the problem [11].

\section{Bioplastic}

Governments try to encourage replacing conventional plastic bags with biodegradable plastic. Biodegradable plastic bags are intended to break down more rapidly than conventional plastic bags, and are, therefore, believed to be less persistent as litter [8]. However, there are no reports on complete biodegradation of those bags [12], and often they contribute to microplastics [13]. Furthermore, due to higher prices of biodegradable resins [14], some plastic bag producers misrepresent the standard for their biodegradable products in marketing their goods to save money [15]. With relatively little information about the waste treatment of biodegradable plastics [16] and in the absence of clear labeling, marking for consumers and/or adequate waste collection, biodegradable plastics could magnify the existing problem of plastics leakage and create further challenges for mechanical recycling [17]. Although plenty of academics have expressed their concerns, the use of compostable plastics has been promoted around the world [18], including some developing countries with relatively poor waste management infrastructure where the likelihood of those products reaching an appropriate waste stream seems low [13].

Nevertheless, some companies offer fully compostable bags which can dissolve in water. However, such products tend to be significantly more expensive than a conventional 
plastic bag [19]. What is more, due to the lack of sufficient infrastructure amongst developing countries, many biodegradable plastic bags will not decompose correctly as they will end up either in landfills or get incinerated [18].

\section{Public involvement}

Zhijun and Nailing both agree [20] governments need to engage with the broader public extensively for a new policy to be successful. System changes must be designed within a specific context; based on a thorough diagnostic of the issue, problem-solving in nature and in consultation with the various stakeholders. Reforms must be sensitive to the environment and its peculiarities. Additionally, identity, actions and choices of individuals are influenced by the concept of habitus. Thus, it is critical to understand what influences public managers' actions and decisions within the specific process in the host environment while taking into consideration public perceptions of value. According to Kollmuss and Agyeman [21], increased knowledge and awareness about environmental dilemmas can change environmental attitudes, influence environmental behaviour and decrease irresponsible human practices towards nature. Similarly, Aminrad et al. claim that by increasing the level of awareness about plastic pollution, it is possible to influence people's behaviour, since awareness correlates with attitudes and willingness to start a change [22] as well as creates a sense of environmental responsibility [23]. In contrast, Hammami et al. [24] notice that there is no difference in plastic utilisation per day between the knowledgeable and non- knowledgeable participants of their study. Authors also observe that although participants know recycling is a way to dispose of plastic products, most of them dispose of it in the dustbin which can be due to an insufficient number of recyclable bins or a gap between the level of awareness and best practice. Abila and Kantola [25] explain the tendency towards pro-environmental behaviour is motivated instead by monetary gains or incentives rather than environmental rationale and both argue that the introduction of financial incentives for recyclables is required in order to boost consumers' participation in the recycling. To conclude, raising awareness can help to manage the correct disposal SUP; however, the financial incentive might be needed, especially in the initial stages.

\section{Extended Producer Responsibility}

Incentivising recycling of SUP may be achieved through the implementation of Extended Producer Responsibility (EPR), which is defined as an environmental policy principle in which a producer's responsibility is extended to the post-consumer stage of a product's life including takeback, recycling and final disposal [26]. It is based on the fact that producers are best-positioned parties to make the required changes regarding collection and recycling to minimise the negative impacts of their products. Not only does the private sector have more capabilities and resources than any other actor but also has the ability to drastically advance the transition towards a circular model [27]. Indeed, by incentivising, EPR for SUP does contribute to a significant increase in recycling rates and reduction of littering [28] as well as encourages smarter and more sustainable design of plastic products [29]. Nevertheless, the current low demand for recycled plastics results in low commodity prices [30] and often is associated with low- value or niche applications [17] which can discourage producers from investing in rather costly EPR facilities [31].

Linderhof et al. [32] argue, however, that the introduction of mandatory EPR initiatives such as a depositrefund scheme for plastic bottles will stimulate companies' cooperation. It can be noted that there has been a shift from voluntary initiatives of producers to the introduction of mandatory programs by governments due to the apparent ability to achieve higher collection and recycling rates [33]. Pazoki and Zaccour [34] argue, however, that governments must come up with a clear definition of a producer as EPR can target producers, importers, brand owners and even users depending on the definition. Equally, policymakers must recognise that different products face varying aftermarket conditions [35]. Perhaps an EPR programme for plastic bags may not be as effective as the one for plastic bottles. Moreover, policymakers must explicitly articulate the range of responsibilities for each supply chain member while equally focusing on the enforcement [35].

\section{Enforcement}

Governments must pay increased attention to the issue of weak enforcement [20][28]. For example, when analysing EPR, there are some small importers who have successfully avoided paying the EPR fee, relying on weak government enforcement [36]. To enable effective enforcement, firstly, there is a need for clear and relevant regulations, as often the provisions in the policy are generic in nature and not effective [37]. Secondly, effective enforcement must form an organic structural system that addresses government regulation, legal sanctions, fines, persuasion, denounciation [38 recycled] as well as the power to prosecute littering offenders [39]. Thirdly, Ijaiya and Joseph [40] observe that the discordance in the relationship among the tiers of government limits the effectiveness of enforcement; therefore, there is a need for a clear division of powers. Fourthly, poor communication among the internal departments as well as the lack of clarity about the roles of the federal and state ministries can further impact poor enforcement [40]. Okorodudu-Fubara [41] observes, however, for the government to function effectively, agencies must be financially viable as inadequate funding might affect environmental law enforcement. Indeed, poor waste management indicates that waste generation is mostly associated with the economic status of a society, their weak economy-social factors affected by the absence of proper environmental legislation, financial management and administrative capacities [42].

\section{Key Performance Indicators (KPI)}

When implementing a new environmental policy, it may be useful to measure the effectiveness of the policy. Key Performance Indicators (KPIs) are indexes used to evaluate the crucial factors related to a defined goal (such as zero single-use plastics policy), and the success of the organisation in achieving this goal depends on these factors. Identifying the crucial factors and following up with them is one way to know how the policy is implemented [43]. Zaman [44] states that a set of indicators is essential for measuring the performance of waste management. Admittedly, Lo-Iacono-Ferreira et al. [45] encourage assessors to consult stakeholders regarding their interest in the new environmental policy. Taking into account the 
stakeholders' interests significantly improves the likelihood of addressing successful action plans. Nevertheless, addressing stakeholders' interests require particular expertise to avoid obstacles in the decision-making process that can lead to paralysis [46].

\section{Manufacturers and recyclers}

Both the European Commission [17] and the EMF [3] acknowledge that to curb SUP effectively, action from all stakeholders in the plastics value chain, including manufacturers and recyclers, is required. When it comes to recycled plastics, manufacturers of plastic articles and packaging have very little or no motivation to take into account the needs of recycling or reuse when designing a product. Plastics tend to be highly customised to meet each producer's functional and aesthetic demands. This diversity can complicate the recycling process, make it costlier, and affect the quality and value of recycled plastic on top of negatively impacting the value of recycles [17]. Vadenbo et al. [47] also mention quality being key as materials must have the ability to fulfil the functionality of the raw materials in order to compete with virgin stock feedstock. Eriksen et al. explain [48] the quality of plastic waste is affected mainly by the contamination level of the recovered plastic. Hence, adequate source separation and sorting will ensure a better quality of recycled plastic material. Growth and expansion of plastic recycling are, therefore, often restrained by insufficient volumes and low quality of collected plastic waste [28]. Perhaps the low volume of recyclables could be linked to public awareness, as discussed in section 2.2 as well as the lack of strict regulations.

\section{Public value and quadruple bottom line}

Finally, initiatives to improve waste management and reduce SUP require the participation of both the public and private sectors [49]. The authorities have a crucial role in leading a strategic change towards a zero SUP society [11] As the system of dependents within the SUP, the supply chain seems to be rather complicated, and the importance of taking the right decisions can be vital. It is crucial to look at the the issue through the lenses of both Public Value (PV) and quadruple bottom line. Blanes [50] argues that often, policymakers construct reforms without considering the specific context of the environment. This could indeed manifest in the lack of in-depth diagnosis, limited consultation with stakeholders or in avoiding the context of the problem. If society is encouraged to move toward a less wasteful reality, the change can be reflected, not only in respect towards nature but also in establishing new measures of impact on the environment, people, as well as the purpose of the decision making.

\section{B. Methodology overview}

Twelve semi-structured interviews with key stakeholders including authorities (both the federal and the state government), city council, environmental government agency as well as recyclers, plastic manufacturers and a private company utilising SUP packaging have been conducted. The stakeholders were selected based on a report of the Malaysian Government that defined the critical role of the Federal and the State Governments, Manufacturers, City Councils, NGOs and Business
Operators as well as recycling facilities for the implementation of SUP policies [1]. Therefore, purposive sampling was chosen as it allows for identifying and selecting information-rich cases related to the phenomenon of interest [51]. Critical figures such as managing directors, chief executives, as well as government or parliament officials, were interviewed for the study as they had access to the appropriate contextual and situated knowledge [52].

Confirming and disconfirming case is pursued to analyse whether the direction of the federal policy resonates with the stakeholders outlined in the policy. The authors aimed to replicate Gale's [53] approach when analysing the gathered data in the case study. Yin [54] believes that a case study is suitable for a research format that attempts to explore a modern phenomenon within a real- life context, which is tackling plastic pollution for this study. A data analysis software called NVivo was used to identify the key themes emerging from the interviews that were visualized in a word cloud. The authors look for themes that were either overarching or mismatching. An analysis of primary qualitative data was undertaken in a manner that aimed to complete a rigorous comparison of topics and concepts extracted from information in interview transcripts highlighting similarities and differences of approaches. The gathered data is coded both manually and using NVivo. These similarities and differences are presented in section three.

\section{RESULTS}

\section{A. Zero single-use plastics (SUP)}

The study shows the government is aware of how much society is dependent on plastic. SUP include plastic bags, plastic bottles, plastic straws, bottle caps and a diverse range of food packaging [3]. A zero SUP policy aims to divert from landfill as much SUP as it is possible by enhancing recycling and composting single-use plastics. Instead of fully banning SUP, the policy aims to replace conventional SUP with a more environmentally friendly solution, therefore, the government must provide support for the businesses to help them transit. The new approach can manifest in refuse, reduce, reuse and recycle attitude or by the transition of the plastic industry from conventional plastic to biodegradable plastics such as SUP made of organic and compostable materials. However, currently, there are no affordable alternatives on the market. Indeed Spencer [19] mentions that there is a high price associated with any alternatives for conventional plastics, which is a barrier when trying to reduce SUP in Penang. Consequently, the study suggests the new definition of zero SUP as an environmental policy that aims to divert from the landfill as much single-use plastics as it is possible by enhancing recycling and composting SUP .

\section{B. Alternatives to conventional plastics}

The study shows the federal government is actively promoting biodegradable plastic and compostable products. The federal government seem to be supportive of SUP only when they are made of bio-plastic, rather than eliminating SUP all together. In contrast, the state of Penang is actively discouraging bioplastic, which is considered not good for the environment. In addition, plastic manufacturers are also 
against the idea of bio-plastic due to its negative impact on the environment as well as due to the high costs of production. Plastic manufacturers are keen to tackle plastic pollution; however, they do not believe the federal government has come up with an appropriate solution to solve the plastic problem ("Replacing the packing you will solve the problem of litter and plastic pollution").

Penang indeed does not support bioplastic, and a state government agency suggests using items that are either fully compostable or reusable such as metal/paper straws or seaweed packaging. On the downside, such alternatives can be life-threating in some cases (Metal drinking straw warning after the death of a woman) [55]. What is more, the price of the alternatives can be a few times more expensive than conventional plastic, and the alternative plastic is often not as durable or versatile as the conventional plastic [19]. In other words, some stakeholders are not supportive of a new policy as they do not consider bio-plastic safe for the environment.

Furthermore, according to recyclers, workers are unable to distinguish a biodegradable bag from a conventional SUP bag. Consequently, both types of plastic are treated in the same way and end up in a landfill or escape to the environment. It confirms that biodegradable plastics without clear labelling for consumers or adequate waste collection, can magnify the existing problem of plastics leakage and create further challenges for mechanical recycling [17]. Therefore, it does seem that the approach towards SUP and waste management can be more holistic. In short, the study indicates gaps from the proposed plastic-pollution policy and its implementation.

\section{Circular approach - recommendations}

\section{Improved waste management system}

The study identifies five key findings that can enhance more circular approach towards SUP in Penang. The plan to replace conventional plastics with bioplastics requires, firstly, a well-developed waste management system to ensure an adequate end of life for compostable bioplastics. Additionally, there is almost no industrial composting available, which reinforces a need for investment in the appropriate facilities. This is crucial in order for bioplastics to be diverted from landfill and processed correctly in Penang. Equally, it is vital to increase the number of recycling points at condominiums, universities or public spaces. Indeed, there might be barriers that impede households from recycling as current practices may be confusing and not accessible. Further research and possibly more awareness campaigns might be needed.

\section{Key Performance Indicators}

Secondly, key performance indicators must be applied to ensure a smooth transition towards a circular model for SUPs. Currently, there are limited criteria which measure how successful environmental initiatives are and how good recycling is in Penang. For example, recycling rates vary from $32 \%$ to $45 \%$ depending on the stakeholder, and there is no substantial proof to back up the numbers. Indeed, the quoted recycling rates seem questionable, especially when compared with an average recycling rate in Europe, which is $45 \%$ [56]. This emphasises a need for clearer and more transparent key performance indicators. Accordingly,
Zaman [44] states that a set of indicators are crucial for measuring the performance of waste management activities

\section{Extended Producer Responsibility (EPR)}

Thirdly, an introduction of a deposit scheme through Extended Producer Responsibility (EPR) can reduce the amount of SUP going to landfill. The challenging nature of the EPR [32] is identified in the study as not all stakeholders are supportive of the idea yet. Some beverage companies are not keen to implement the deposit scheme voluntarily; that is why the government should consider introducing a mandatory deposit scheme in the country. One of the reasons why companies prefer to use virgin material for the packaging is because as recycled plastics are considered highly contaminated; therefore they are believed to be of low value [48]). This puts emphasis on the role of the federal government to consider a mandatory [33] Extended Producers Responsibility scheme.

\section{Policy Enforcement}

Fourthly, a well-researched matter of weak policy enforcement [20] is identified in the study. Authorities must pay attention to the enforcement through positioning a mandatory approach towards environmental legislation as the majority of stakeholders agree that a voluntary approach is not very efficient in Malaysia. Equally, stakeholders agree that there is a need for a law to be created to support enforcement practices. In contrast, the state government is exploring the concept of the "Educational Enforcement" where actions are triggered by a high level of awareness and a sense of duty. Such a "disciplined society" may sound rather idyllic and may be difficult to achieve when comparing with opinions from other stakeholders who are calling for controlled and robust legislation to enhance the enforcement. Additionally, a coordinated approach supporting either a voluntary or a mandatory approach is needed from authorities to ensure a smooth transition towards a circular economy.

\section{Clarity of communications}

To enhance the circular approach towards SUP, a coordinated approach from both the federal and the state governments is required. Some stakeholders find that the local and federal governments lack clear and coordinated top-down communications (e.g. two ministers, one pushes hard on single-use plastics, and the other is trying to reduce the waste). Both the federal and the state governments need to agree on coordinated roles and strategies when addressing SUPs. This highlights a need for the authorities to engage with all stakeholders extensively to ensure a successful implementation of new policies. These can become an ongoing barrier for the implementation of further developments of zero single-use policies if not addressed in a timely manner.

\section{Federal government engaging openly with all stakeholders}

Although the federal government confirms key stakeholders have been consulted on the new environmental policy, some key stakeholders expressed their concern that their voices have not been heard ("The Government did not consult with us properly). Additionally, numerous stakeholders are not supportive of bio-plastic being an 
appropriate solution in addressing plastic pollution. However, the federal government does not seem to consider these concerns. Thus, there is a need for better engagement with stakeholders to look at the problem more holistically for a more innovative and effective solution.

To sum up, the transition towards a circular economy is complex and can be challenging. The state must work effectively with the federal government to ensure a coordinated approach in tackling plastic pollution as well as create an open dialogue with all the stakeholders. A mandatory Extended Producer Responsibility can encourage residents to recycle while a robust and transparent waste management system will ensure bioplastics and compostable SUP are diverted from landfill. Lastly, Key Performance Objectives must be set to track the progress while addressing the complexity of weak policy enforcement.

\section{CONCLUSIONS}

To conclude, this study aimed to explore how the state of Penang can move towards a zero single-use plastics by 2030 to comply with a new federal environmental policy. The findings show that both federal and state governments play a crucial role in leading the change by establishing the direction, engaging with the stakeholders, and co-creating policies to implement, enforce, and monitor the new environmental policy. Thus, to achieve a zero SUP, there is a need to co-create and co-produce value with identified stakeholders. With an investment in alternative, fully compostable or recyclable materials along with an improved and integrated waste management system, it may be possible to divert a significant amount of single-use plastics from the landfill. Consequently, Penang can become one of the first states in Malaysia that practices zero single-use plastics.

\section{REFERENCES}

[1] Malaysian Government. Malaysia's Roadmap Towards Zero SingleUse Plastics [Online]. [Accessed 9 July 2019]. Available from: https://www.mestecc.gov.my, 2018.

[2] Hu, Y., He, X. and Poustie, M. Can Legislation Promote a Circular Economy? A Material Flow- Based Evaluation of the Circular Degree of the Chinese Economy. Sustainability. [Online].10(4),p.990, 2018. [Accessed 14 August 2019]. Available from: https://www.researchgate.net.

[3] EMF. The New Plastics Economy [Online]. Ellen MacArthur Foundation. [Accessed 6 June 2019]. Available from: https://www.ellenmacarthurfoundation.org, 2016.

[4] Hong, M. and Chen, E. Chemically recyclable polymers: a circular economy approach to sustainability. Green Chemistry. [Online].19(16),pp.3692-3706, 2017. [Accessed 8 August 2019]. Available from: https://pubs.rsc.org,

[5] Meidiana, C. and Gamse, T. Development of Waste Management Practices in Indonesia. European Journal of Scientific Research. [Online]. 40(2),pp.199-210, 2010. [Accessed 3 August 2019]. Available from: https://s3.amazonaws.com.,

[6] Xanthos, D. and, Walker T. 2018. A call for Canada to move toward zero plastic waste by reducing and recycling single-use plastics. Resources, Conservation and Recycling. [Online]. 133,pp.99-100, 2018. [Accessed 9 August 2019]. Available from: https://libkey.iol,

[7] Viscusi, W., Huber, J., Bell, J. and Cecot, C. Discontinuous Behavioral Responses to Recycling Laws and Plastic Water Bottle Deposits. American Law and Economics Review. [Online]. 15(1),pp.110-155, 2013. [Accessed 7 August 2019]. Available from: https://watermark-silverchair-com.ezproxy.lib.gla.ac.uk

[8] Green, D., Boots, B., Blockley, D., Rocha, C. and Thompson, R. Impacts of Discarded Plastic Bags on Marine Assemblages and Ecosystem Functioning. Environmental Science \& Technology. [Online]. 49(9),pp.5380-5389, 2015. [Accessed 8 August 2019]. Available from: https://pubs-acsorg.ezproxy.lib.gla.ac.uk/doi/10.1021/acs.est.5b0

[9] Afroz, R., Rahman, A., Masud, M. and Akhtar, R. The knowledge, awareness, attitude and motivational analysis of plastic waste and household perspective in Malaysia. Environmental Science and Pollution Research. [Online]. 24(3),pp.2304-2315, 2016. [Accessed 7 August 2019]. Available from: https://link.springer.com,

[10] Barneveld, J., Veen, G., Enenkel, K., Mooren, C., Talman-Gross, L., Eckartz, K., Ostertag, K., Duque- Ciceri, N., Fischer, T., Gama, M., Scheidt, L., Wilts, H., Schäfer, L. and Fischer, S. Regulatory barriers for the Circular Economy - Lessons from ten case studies [Online]. Amsterdam: Technopolis Group. [Accessed 7 July 2019]. Available from: https://ec.europa.eu,2019.

[11] Zotos, G., Karagiannidis, A., Zampetoglou, S., Malamakis, A., Antonopoulos, I., Kontogianni, S. and Tchobanoglous, G. Developing a holistic strategy for integrated waste management within municipal planning: Challenges, policies, solutions and perspectives for Hellenic municipalities in the zero-waste, low-cost direction. Waste Management. [Online]. 29(5),pp.1686-1692, 2009. [Accessed 10 August 2019]. Available from: https://wwwsciencedirect-com.ezproxy.lib.gla.ac.uk,

[12] Nauendorf, A., Krause, S., Bigalke, N., Gorb, E., Gorb, S., Haeckel, M., Wahl, M. andTreude, T. Microbial colonization and degradation of polyethylene and biodegradable plastic bags in temperate finegrained organic-rich marine sediments. Marine Pollution Bulletin. [Online]. 103(1- 2),pp.168-178, 2016. [Accessed 2 August 2019]. Available from: https://pdf.sciencedirectassets.com,

[13] Napper, I. and Thompson, R. Environmental Deterioration of Biodegradable, Oxo- biodegradable, Compostable, and Conventional Plastic Carrier Bags in the Sea, Soil, and Open-Air Over a 3-Year Period. Environmental Science \& Technology. [Online]. 53(9),pp.4775-4783, 2019. [Accessed 1 August 2019]. Available from: https://pubs-acs-org.ezproxy.lib.gla.ac.uk,

[14] Demirbas, A. Biodegradable Plastics from Renewable Resources. Energy Sources, Part A: Recovery, Utilization, and Environmental, Effects. [Online]. 29(5),pp.419-424, 2007. [Accessed 9 August 2019]. Available from: https://link.springer.com/,

[15] Bateman, R. Officials: Some mislabel bags as biodegradable. Plastics News. [Online]. 19(15),pp.4-4, 2019. [Accessed 8 August 2019].Available http://web.a.ebscohost.com.ezproxy.lib.gla.ac.uk.

[16] Hermann, B., Debeer, L., De Wilde, B., Blok, K. and Patel, M. To compost or not to compost: Carbon and energy footprints of biodegradable materials' waste treatment. Polymer Degradation and Stability. [Online]. 96(6),pp.1159-1171, 2011. [Accessed 7 August 2019]. Available from: flandfilhttps://www.sciencedirect.com,

[17] European Commission. A European Strategy For Plastics in a Circular Economy [Online]. The European Commission. [Accessed 6 July 2019]. Available from: http://ec.europa.eu/, 2016.

[18] Quecholac-Piña, X., García-Rivera, M., Espinosa-Valdemar, R., Vázquez-Morillas, A., Beltrán- Villavicencio, M. and CisnerosRamos, A. Biodegradation of compostable and oxodegradable plastic films by backyard composting and bioaugmentation. Environmental Science and Pollution Research. [Online]. 24(33),pp.25725-25730, 2016. [Accessed 3 August 2019]. Available from: https://link- springer-com.ezproxy.lib.gla.ac.uk,

[19] Spencer, C. Plant-based plastics going to landfill. BBC News. [Online]. [Accessed 10 August 2019]. Available from: https://www.bbc.com, 2019.

[20] Zhijun, F. and Nailing, Y. Putting a circular economy into practice in China. Sustainability Science. [Online]. 2(1),pp.95-101, 2007. [Accessed 14 July 2019]. Available from: https://link.springer.com

[21] Kollmuss, A. and Agyeman, J. Mind the Gap: Why do people act environmentally and what are the barriers to pro-environmental behavior?.Environmental Education Research. [Online]. 8(3),pp.239-260, 2002. [Accessed 9 August 2019]. Available from: https://www.tandfonline.com 
[22] Aminrad, Z., Zakariya, S., Hadi, A. and Sakari, M. Relationship Between Awareness, Knowledge and Attitudes Towards Environmental Education Among Secondary School Students in Malaysia. World Applied Sciences Journal. [Online]. 22(9),pp.13261333,2013. [Accessed 8 August 2019]. Available from: https://pdfs.semanticscholar.org

[23] Bravo, M., de los Ángeles Gallardo, M., Luna-Jorquera, G., Núñez, P., Vásquez, N. and Thiel, M. Anthropogenic debris on beaches in the SE Pacific (Chile): Results from a national survey supported by volunteers. Marine Pollution Bulletin. [Online]. 58(11),pp.17181726, 2009. [Accessed 1 August 2019]. Available from: https://www-sciencedirect-com.ezproxy.lib.gla.ac.uk

[24] Hammami, M., Mohammed, E., Hashem, A., Al-Khafaji, M., Alqahtani, F., Alzaabi, S. and Dash, N. Survey on awareness and attitudes of secondary school students regarding plastic pollution: implications for environmental education and public health in Sharjah city, UAE. Environmental Science and Pollution Research. 24(25),pp.20626-20633, 2017.

[25] Abila, B. and Kantola, J. The Perceived Role of Financial Incentives in Promoting Waste Recycling-Empirical Evidence from Finland. Recycling. [Online]. 4(1),p.4, 2019. [Accessed 1 August 2019]. Available from: https://www.mdpi.com

[26] OECD. The State of Play on Extended Producer Responsibility (EPR): Opportunities and Challenges [Online]. Tokyo: OECD, 2014. [Accessed 15 July 2019]. Available from: https://www.oecd.org

[27] Geissdoerfer, M., Savaget, P., Bocken, N. and Hultink, E. The Circular Economy - A new sustainability paradigm?. Journal of Cleaner Production. [Online]. 143,pp.757-768, 2017. [Accessed 9 August 2019]. Available from: https://www.sciencedirect.com

[28] Leal Filho, W., Saari, U., Fedoruk, M., Iital, A., Moora, H., Klöga, M. and Voronova, V. An overview of the problems posed by plastic products and the role of extended producer responsibility in Europe. Journal of Cleaner Production. [Online]. 214,pp.550-558, 2019. [Accessed 15 July 2019]. Available from: https://wwwsciencedirect-com.ezproxy.lib.gla.ac.uk/

[29] Watkins, E., Gionfra, S., ten Brink, P., Schweitzer, J., Pantzar, M. and Janssens, C. EPR in the EU Plastics Strategy and the Circular Economy: A focus on plastic packaging [Online]. [Accessed 15 July 2019]. Available from: https://ieep.eu/ 2017.

[30] Milios, L., Holm Christensen, L., McKinnon, D., Christensen, C., Rasch, M. and Hallstrøm Eriksen, M. Plastic recycling in the Nordics: A value chain market analysis. Waste Management. [Online]. 76,pp.180-189, 2018. [Accessed 9 August 2019]. Available from: http://www.sciencedirect.com

[31] Hogg, D. and Sherrington, C. A Comparative Study on Economic Instruments Promoting Waste Prevention [Online]. Bruxelles Environnement. [Accessed 9 August 2019]. Available from: https://www.eunomia.co.uk, 2011

[32] Linderhof, V., Oosterhuis, F., van Beukering, P. and Bartelings, H. Effectiveness of deposit- refund systems for household waste in the Netherlands: Applying a partial equilibrium model. Journal of Environmental Management. [Online]. 232,pp.842-850, 2019. [Accessed 6 August 2019]. Available from: https://libkey.io/libraries

[33] Turner, J. and Nugent, L. Charging up Battery Recycling Policies: Extended Producer Responsibility for Single-Use Batteries in the European Union, Canada, and the United States. Journal of Industrial Ecology. [Online]. 20(5),pp.1148-1158, 2015. [Accessed 10 August 2019]. Available from: https://onlinelibrary-wileycom.ezproxy.lib.gla.ac.uk

[34] Pazoki, M. and Zaccour, G. Extended producer responsibility: Regulation design and responsibility sharing policies for a supply chain. Journal of Cleaner Production. [Online]. 236,p.117516, 2019.

[35] Ogushi, Y. and Kandlikar, M. Assessing Extended Producer Responsibility Laws in Japan. Environmental Science \& Technology. [Online]. 41(13),pp.4502-4508, 2007. [Accessed 10 August 2019]. Available from: https://pubs.acs.org

[36] Lindhqvist, T., Tojo, N. and Davis, G. OECD Seminar on Extended Producer Responsibility, EPR: Programme Implementation and Assessment [Online]. Paris, France, 2019. [Accessed 1 August 2019]. Available from: https://pdfs.semanticscholar.org

[37] Agamuthu, P. and Victor, D. Policy trends of extended producer responsibility in Malaysia. Waste Management \& Research.
[Online]. 29(9),pp.945-953, 2011. [Accessed 15 July 2019]. Available from: https://journals-sagepub-com.ezproxy.lib.gla.ac.uk

[38] Cao, H., Shao, H. and Cai, X. Analysis of Environmental Law Enforcement Mechanism Based on Economic Principle. IOP Conference Series: Earth and Environmental Science. [Online]. 94,p.012188, 2017. [Accessed 10 August 2019]. Available from: https://iopscience.iop.org

[39] Quartey, E., Tosefa, H., Danquah, K. and Obrsalova, I. Theoretical Framework for Plastic Waste Management in Ghana through Extended Producer Responsibility: Case of Sachet Water Waste. International Journal of Environmental Research and Public Health. [Online]. 12(8),pp.9907- 9919, 2015. [Accessed 1 August 2019]. Available from: https://www.mdpi.com/

[40] Ijaiya, H. and Joseph, O. Rethinking Environmental Law Enforcement in Nigeria. Beijing Law Review. [Online]. 05(04),pp.306-321, 2014. [Accessed 5 August 2019]. Available from: https://file.scirp.org

[41] Okorodudu-Fubara, M. Law of Environmental Protection.. Caltop Publications Nigeria Limited, 1998.

[42] Muniafu, M. and Otiato, E. Solid Waste Management in Nairobi, Kenya. A case for emerging economies. Journal of Language, Technology \& Entrepreneurship in Africa. [Online]. 2(1), 2010. [Accessed 17 August 2019]. Available from: https://www.scopus.com

[43] Kerzner, H. Project management metrics, KPIs, and dashboards: a guide to measuring and monitoring project performance [Online]. John Wiley \& Sons, 2017. [Accessed 10 August 2019]. Available from: https://books.google.com

[44] Zaman, A. Identification of key assessment indicators of the zero waste management systems. Ecological Indicators. [Online]. 36,pp.682-693, 2014. [Accessed 8 August 2019]. Available from: https://www.sciencedirect.com

[45] Lo-Iacono-Ferreira, V., Capuz-Rizo, S. and Torregrosa-López, J. Key Performance Indicators to optimize the environmental performance of Higher Education Institutions with environmental management system - A case study of Universitat Politècnica de València. Journal of Cleaner Production. [Online]. 178,pp.846-865, 2018. [Accessed 10 August 2019]. Available from: https://pdf.sciencedirectassets.com

[46] White, J. How Much Attention to Stakeholder Interests? A Practitioner's View of the Need to Take Account of Stakeholder Interests. Global Policy. [Online]. 6(4),pp.501-503, 2015.

[47] Vadenbo, C., Hellweg, S. and Astrup, T. Let's Be Clear(er) about Substitution: A Reporting Framework to Account for Product Displacement in Life Cycle Assessment. Journal of Industrial Ecology. [Online]. 21(5),pp.1078-1089, 2016. [Accessed 9 August 2019]. Available from: http://onlinelibrary.wiley.com

[48] Eriksen, M., Damgaard, A., Boldrin, A. and Astrup, T. Quality Assessment and Circularity Potential of Recovery Systems for Household Plastic Waste. Journal of Industrial Ecology. [Online]. 23(1),pp.156-168, 2018. [Accessed 9 August 2019]. Available from: https://onlinelibrary-wiley-com.ezproxy.lib.gla.ac.uk

[49] Kirama, A. and Mayo, A. Challenges and prospects of private sector participation in solid waste management in Dar es Salaam City, Tanzania. Habitat International. [Online]. 53,pp.195-205, 2016. [Accessed 11 August 2019]. Available from: http://ttps://www.sciencedirect.com

[50] Blanes, R. 2017. Smart policy for public value: strategic management in public sector reform. PhD thesis, University of Glasgow, 2017.

[51] Palinkas, L., Horwitz, S., Green, C., Wisdom, J., Duan, N. and Hoagwood, K. Purposeful Sampling for Qualitative Data Collection and Analysis in Mixed Method Implementation Research. Administration and Policy in Mental Health and Mental Health Services Research. [Online]. 42(5),pp.533-544, 2013. [Accessed 14 August 2019]. Available from: https://www.ncbi.nlm.nih.gov

[52] Mason, J. 2002. Qualitative Researching [Online] 3rd ed. London: Sage Publications. [Accessed 12 August 2019] 